\title{
Analysis on Training the Integrated Language Competence of Students based on the Perspective of English Speech
}

\author{
Juan $\mathrm{Yu}$ \\ School of Foreign Languages, Wuhan Donghu University
}

\begin{abstract}
It is well known that in the process of communication, the competence in making speeches is one of the important means, which is a very practical skill. In the process of teaching, English speaking activities are used as aided methods, thus not only promoting students to effectively cultivate the competence in the language use in the communication and simultaneously get inspired in learning. Then, the learned knowledge and skills are fully utilized by students, and the students' integrated language competence is expanded to some extent.
\end{abstract}

Keywords- English Speech; Students' Integrated Language Competence; Training; Analysis

\section{Introduction}

Speech is an art and can help exercise the learners' language and thinking competence and improve their interest in learning, so it is has always been widely focused. Under the background of the deepened deform in foreign language education, English language learners more frequently participate in English speeches, and therefore, the students' English speaking competence is emphasized more greatly. In this paper, training the students' integrated language competence is introduced based on the perspective of English speeches, for the ultimate purpose of better promoting the development of foreign language education in China and the all-round development of students.
2. The background for training the students' integrated language competence from the perspective of English speeches

A person's competence in making speeches is essential to success, but also an important method to get involved in communication. Competence in making speeches is a practical skill and also shows its true value from multiple dimensions. In the western countries, great importance is always attached to speeches [1]. In China, English learning has been gradually popularized, thus promoting English speech to manifest its important role and significance. The main reason is that making speeches can promote students to gain good training in language use competence in the communication process. For example, the collection, analysis and synthesis of arguments are helpful for the cultivation of self-confidence and creative thinking. At present, the college students' English skills are obviously improved, but there are still some problems and deficiencies in language communication competence. This is mainly because that the exercises of language forms are overstressed in China's oral English teaching; even though the context teaching is effectively integrated and promotes the students' language learning and training cultural environment to be enhanced to some extent, most students only learn for practicing the language and do not really make use of the arguments and the effective organization of the viewpoints. As a result, it is difficult to make the language more convincing and communicate with the audiences, and then the training in the language communication competence only rests on the surface. Relevant scholars believe that a corresponding reform is 
required in foreign language education, because in the training of language skills, imitation practice is only emphasized, but the cultivation of the students' competence in analyzing problems, thinking, innovation, and solving problem independently is ignored. Under the background of China's new curriculum standard, the realization of the students-centered teaching objectives is valued; training the students' cultural literacy is seen as the core of education, so that students can learn how to learn and become brave in making innovation, and ultimately again an all-round development. Thus, English speech as an aided teaching method is of important practical significance to the implementation of the syllabus and training the students' integrated language competence [2].

\section{The role of English speeches in training the integrated language competence}

\subsection{Training the four major skills}

In the process of English learning, the four major skills refer to listening, speaking, reading and writing, which are also the core competences in the language. The role of English speeches in training the four major skills is discussed and studied as follows.

First, English speech has always played an important positive role in training the receptive skills. Receptive skills mainly refer to listening and reading competences, which are the major language input skills. Listening and reading competences also play a fundamental role in English speeches. To promote the students' speaking competence to improve, the key lies in frequently practicing listening. For example, the students are required to very commonly listen to the language materials similar to English radios or different forms of English speeches. On this basis, the listening competence will be effectively improved through repeated language exposures. The reading competence also possesses the same importance. The competence in English reading can directly help expand the students' field of vision and also make the students' vocabulary and grammar consolidated. English reading belongs to the stage of prophase preparation, but also is a process of students to accumulate and think about materials.

Second, English speech also plays an important role in training the students' output skills. Output skills mainly include speaking and writing skills, which are regarded as language output skills. Some scholars think that English speech is a practice of language output, which can not only promote the students' competence in information processing to fully play and the language skills to improve [3]. As is known to all, English speech demands oral English expression competence, in which pronunciation and intonation are important and intuitive factors, but also the keys to convey the information. By English speech training, students can learn accurate English pronunciation and how to speak elegantly. Obviously, in the process of training the students' speaking competence, oral imitation is necessarily stressed, so that the oral competence is improved in the practice over a long period of time. When a speech is prepared by students, the different materials accumulated by them are demanded to effectively convert into written texts. In the whole process, these materials play a positive role in planning, modifying and refining the entire speech structure. The students' self-confidence and awareness in communication have been enhanced obviously in the practice of speech. Simultaneously, this process is of vital significance to improve English speaking and writing skills. When the students' output skills are trained, English speech plays an importance role, because everyone is willing to make a good performance in public. Influenced by this driving force, students gradually learn to actively mobilize their own subjective initiative and eventually accomplish an ideal effect. Most scholars, after a long-term study, found that the process of students to prepare an English speech exerted a positive effect on commanding the 
language knowledge; repeated consideration and deliberation and many changes promoted the language knowledge to be effectively internalized.

Third, English speech promotes the students' integrated English competence to play an effect from many aspects. Speech is in the scope of the deep ideological communication among people, which can comprehensively test the comprehensive quality of a student. Oral English teaching, giving top priority to speeches, plays a positive role in promoting the students' language proficiency, cultural literacy, logical thinking skills, and application and communication skills. However, a long process is a must in order to achieve an effective improvement in the above mentioned competences. Students, in English speech training, will deeply understand the important role of social hot issues and current events. Students can widely accumulate the related knowledge and know well the cultural deposits of every country when they are learning the culture of various countries in the world. Meanwhile, the students' horizons are broadened, and thus, they can think and solve problems from multiple perspectives. In recent years, the contents in English speech contest and the speech themes for the contestants are increasingly creative and challenging.

Thus, it is known that the integration of the students' English comprehensive skills is effectively promoted through English speech, thus not only exercising the students' competence in listening, speaking, reading and writing, and also promoting their mental quality, adaptability, and knowledge experience to improve.

\section{English speech course activities based on the perspective of English speeches}

First, for beginners to make English speeches, imitation is the most basic learning content, but also the beginning of the language expression and mastering the speech style. Students can watch the successful speech examples, and carry out empathic learning, deep analysis or exploration using the audio-visual presentation materials to actively imitate and compare, and then discover better points fit with their own development.

Second, a conventional way of training is to ask students to assign a topic and make a speech, discuss without restriction, and carry out debate and speech training, for the ultimate goal of achieving an improvement to the students' communication competence. In this process, students only pay attention to a small aspect, but they can have more active thinking and create innovative ideas through free discussion or debate. Good communication competence means that students can better express ideas and points using the oral language. Specifically, students can independently think and analyze a problem and also their ideas about it make sense. In the form of free discussion and debate, students are promoted to think from multiple angles and also receive correct guidance from the teachers. Within the groups, speech practice and mutual feedback are required to conduct, so as to constantly increase the confidence of the students and promoting them to master more skills.

Third, the training in speeches-related skills promotes the conventional training to be consolidated. Some scholars think that the main reason why a speech fails lies in the insufficient experience and skills, and thus, it is seen that simple imitation is impracticable and the speeches-related skills are necessarily known and mastered well [5]. Through practical training, students are promoted to ease their nervous problem and better control the emotion when making a speech in public. Thus, the nervous emotion is effectively converted to positive factor for securing the success of the speech.

Fourth, test and training are dynamically combined together; the ways of training are innovative and improved well. Making a speech is a senior commutative activity, in which accurate language use, viewpoints coherence, logic meticulousness, and sufficient arguments are highly required. The main purpose of the test 
is for enhancing the students' self-awareness and promoting them to be more initiative.

Fifth, in general speech training, the reasonable use of basic competences and skills is emphasized, and the mechanic speaking way is necessarily broken. Therefore, students need to actively get involved in speech activities and further enrich their experience in making speeches. In a real speech environment, students can truly feel the inner world, better draw up conclusions, and learn new knowledge about language and culture, so that their integrated language competence and quality are improved.

\section{Conclusion}

In the modern life, speech is a very important activity form in language communication and plays an important role in training the multi-thinking of students. The main purpose of English speech is to effectively improve the students' competence in foreign language learning and practical application, train their logical thinking, and promote them to clearly express their own ideas and opinions in English, but not to let them become speakers. Under the requirements of the current English syllabus, this teaching method is the most suitable. In the syllabus, teachers are required to positively cultivate the students' competence in learning, communication and innovation, aiming to promote the students to attain an all-round development. The context of English speeches also plays a positive influence on training the students' integrated language use competence.

\section{References}

[1] Caihong Guang, Jia Guo, Wanying Yang, et al. The Cultivation of the Students' Comprehensive Quality through English Speeches [J]. Journal of Changzhi College, 2014 (3): 109-111.

[2] Minjie Zhu. Train the Students' Comprehensive Quality through English Speeches [J]. Overseas English, 2013 (2): 259-261.

[3] Shanshan Su. Analysis on the Role of English Speeches and Debate Courses in Improving English Major Students' Comprehensive Ability [J]. Crazy English (Teachers Edition), 2014 (2): 50-51, 71.

[4] Xiaomeng Liu, Minyan LIU. Improve Students' Comprehensive Ability by English Speaking Teaching [J]. China's School Education, 2013 (10): 84.

[5] Binbin Qin. Discussion on the Quality-oriented Education in English Speech Teaching [J]. Journal of University of Education, 2014 (14): 43-44. 